PRODUCTION

ENGINEERING ARCHIVES
2015, Vol. 6, No 1, pp 45-48

ISSN 2353-5156 (print version)

ISSN 2353-7779 (online version)

\title{
Microstructural evaluation of the lacquered layer quality after corrosion load
}

\author{
Jaroslava Svobodova ${ }^{1}$ \\ ${ }^{1}$ Faculty of Production Technology and Management, J.E. Univerzity in Ústí nad Labem, Pasteurova 3334/7, Ústí nad Labem, Czech Repub- \\ lic, +420 475285 550, svobodova@fvtm.ujep.cz
}

\begin{abstract}
Surface pre-treatment is one of the most important steps before applying the final surface treatment. These pre-treatments, like phosphating, alkaline degreasing, pickling in acids, is used to remove impurities from the surface of the base material and to create appropriate conditions for adhesion of the final coating (metal coatings, organic coatings). Currently are on the rise surface treatments technologies, which are based on nanotechnology. It's a new generation of chemical products for the chemical surface preparation. This paper deals with the evaluation of microstructure of painted sheet metal after corrosion load with salt spray in the corrosion chamber. Metal sheets used for the experiment have been produced from low-carbon non alloy steel. For pre-treatment of the sheet metal was used alkaline degreasing (CC), iron phosphating (Feph) and nanotechnology based product Alfipas ( $\mathrm{Zr}$ ) in combinations: group A - CC $+\mathrm{Zr}$, group B $-\mathrm{Feph}+\mathrm{Zr}$ and group $\mathrm{C}-\mathrm{CC}+\mathrm{Feph}+\mathrm{Zr}$. The aim of this paper is to analyze the behavior of painted sheet metal after corrosion load and evaluate the effect of pretreatment to resistance of painted surface layer.
\end{abstract}

Key words - chemical pre-treatments, steel substrate, nanotechnology, iron phosphating, microstructural analysis

\section{Introduction}

With the development of manufacturing technologies are increasing demands for machine functions and structures research, development and production of new ways to protect the surface of materials is accelerating and strives to manufacture more efficient means acting against corrosion. One of these resources is also the use of nanotechnology in the field of surface treatments (MATERne T. 2012, VoeVodin A. A. 2004, KUŚMIERCZAK S. 2012). The nanotechnology also covers nanolayers, whose purpose is to protect the material surface corrosion. These nanolayers are developed in order to improve the existing funds for corrosion protection surface or in lieu thereof. Nanopassivating layers in future could replace classical phosphate for several reasons: technological, economic and environmental (CAVALEIRO, A. 2006, KLIMECKATATAR, D. 2014). Nanolayers Alfipas is from technological point of view (compared to iron phosphating): applicable at lower temperatures, less time-consuming application, does not produce waste sludge, has universal application for the pre-treatment of steel, galvanized iron or aluminium, easier method of disposal etc. Alfipas is zirconium passivation creating on the surface of the material a layer of inorganic material based on silanes. The basis of these nanoproducts are highly reactive silanes which produces the reaction material surface chemical bond. These silanes form a highly cross linked layer on the surface of the inorganic material with a thickness from 50 to $100 \mathrm{~nm}$ (MATERNE T. 2012, Voevodin A. A. 2004, Ndreatta F. 2011). With this layer formed on the surface of the material 
barrier effect of increasing the corrosion resistance of the material, especially in combination with subsequent powder coating. The inorganic layer is defined as a highly cross linked film firmly anchored to the material surface through the chemical bond of $\mathrm{Si}$ - O M (M-base material). Preparations based on nanotechnology are mostly multimetal. This means that one product may be used for the multiple materials (materials of $\mathrm{Fe}, \mathrm{Al}$ materials). These products are virtually waste-free, so this technology meets the strict EU legislative regulation in the field of environmental protection (ADHIKARI, SAIKAT, K. A. 2011, SZKLARZYK, P., KLIMECKA-TATAR, D., SYGUT, P., LIPIŃSKY, T. 2014, NDREATTA F. 20118). Thanks nanolayers are extended and improved possibilities of corrosion protection materials and surface treatment materials.

\section{Experimental material}

The basic material for the experiment was selected Q-panel Fe - low-carbon, unalloyed, steel material. This material is intended for laboratory use, namely to test protective coatings and various types of surface preparation.

The base material is chemically pre-treated with alkaline degreasing, iron phosphating and nanopassivating product Alfipas. Surface pre-treatments were applied in the following combinations and thus creating three groups of materials:

- Alkaline degreasing (CC) + Alfipas (Zr) - group A

- Iron phosphate (Feph) + Alfipas (Zr) - group B

- Alkaline degreasing (CC) + Iron phosphate (Feph) + Alfipas (Zr) - group C

The powder coating TIGER Drylac ${ }^{\circledR}$ Series 29 light gray was applied to the surface of the experimental samples after performing of the chemical pretreatments.

\subsection{Corrosion load}

Experimental samples were loaded in the corrosive salt spray chamber Liebisch ${ }^{\circledR}$. Working conditions of the corrosion chamber were set according to CSN EN ISO 9227.

Before inserting into the corrosion chamber samples were provided with cross-cut according to CSN EN ISO 17872. The cut was into the surface of painted sheet metal made due to subsequent evaluation of de- lamination and corrosion around the cut according to CSN EN ISO 4628-8.

\section{Microstructural analysis}

Microstructural analysis was performed by confocal laser microscope Olympus LEXT 3100. Within microstructure analysis was carried out the evaluating of the paint layer behaviour after corrosion load. The pre-treatment of the material have fundamental importance for the quality of the final product. Illustratively were selected three representatives from each of one type of pre-treatment the surface. Designation of experimental samples is shown in Table 1.

From all the samples were prepared metallographic samples. Samples were taken from the place where not to remove the lacquer layer delamination (a) and from the cutting area where there is a complete separation or peeling paint (b). The paper presents documentation of samples after $480 \mathrm{~h}$ and $1000 \mathrm{~h}$. The experiments were tested, of course, many more samples in order to compare results and for statistic evaluation.

Table 1. Designation of the experimental samples

\begin{tabular}{|c|c|c|}
\hline \multicolumn{3}{|c|}{ Corrosion test time } \\
\hline $\mathbf{4 8 0} \mathbf{~ h}$ & $\mathbf{7 2 0} \mathbf{~ h}$ & $\mathbf{1 0 0 0} \mathbf{~}$ \\
\hline $\mathrm{A} 1-1$ & $\mathrm{~A} 2-1$ & $\mathrm{~A} 3-1$ \\
\hline $\mathrm{B} 1-3$ & $\mathrm{~B} 2-3$ & B3-3 \\
\hline C1-1 & C2-1 & C3-1 \\
\hline
\end{tabular}

\section{Microstructural evaluation of the samples after 480 hours corrosion load}

From the samples tested after $480 \mathrm{~h}$ loading in the corrosive salt spray chamber has the best results combination of pre-treatment CC + Feph + Zr. By the sample C1-1, as documented in Fig. 5., is evident uniform paint layer intact. Lacquer excellently adheres to the base material. Likewise it is with samples A1-1 (Fig. 1.) and B1-3 (Fig. 3.) at the place of sampling without delamination (a). Significant differences can be observed in Fig. 2., 4. and 6. For sample A1-1 is apparent almost detached lacquer layer and the uneven surface and corrosion of the base material. By the sample of B1-3 we can see complete separation of the lacquer layer. The sample surface is visible at the cutting un- 
even corrosion up to a depth of $160 \mu \mathrm{m}$. The surface surrounding the cut is infected mainly by uniform corrosion. The best results, as already mentioned, have the sample C1-1. Painted layer is broken at the incision site. From Fig. 6. it is clear, that the lacquer layer is under corroded and although incipient corrosion of the base material did not completely peel up lacquer layer, as is the case for samples A1-1 and B1-3.

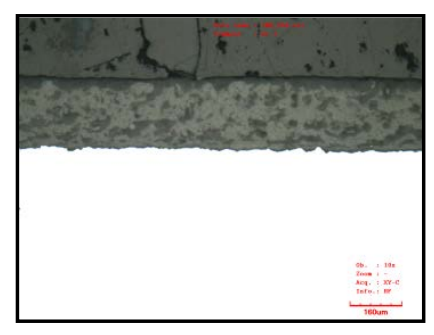

Fig. 1. Lacquered layer A1-1 (a)

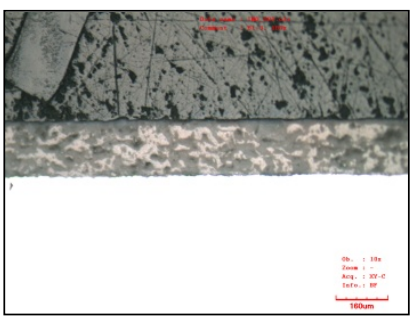

Fig. 3. Lacquered layer B1-3 (a)

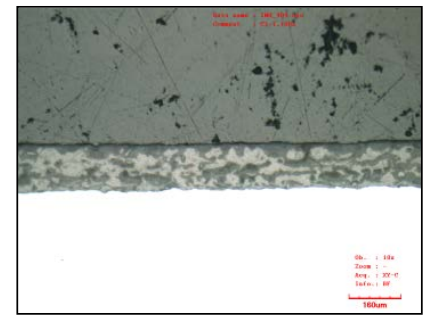

Fig. 5. Lacquered layer C1-1 (a)

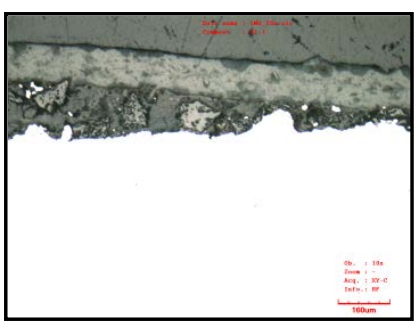

Fig. 2. Lacquered layer after delamination A1-1

(b)

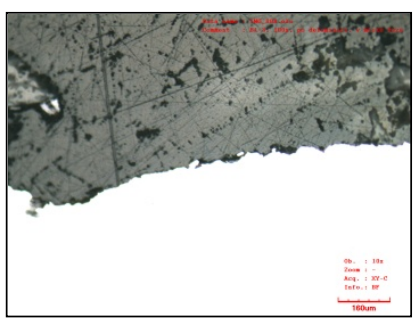

Fig. 4. Surface after delamination B1-3 (b)

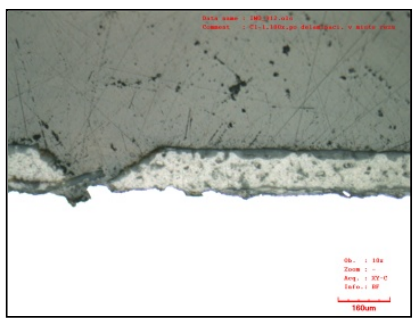

Fig. 6. Lacquered layer after delamination C1-1

(b)

\section{Microstructural evaluation of the samples after 1000 hours corrosion load}

After corrosion load in the corrosion chamber with salt spray after delamination occurred completely peel of the surface layer of the coated material for all samples. The differences between the type of pre-treatment and surface combinations are within the scope of cor- rosion and the amount of corrosion products on the surface of the material. In sample A3-1 (Fig. 8.) is uneven surface attacked by uniform corrosion. On the surface of the material are evident corrosion products.

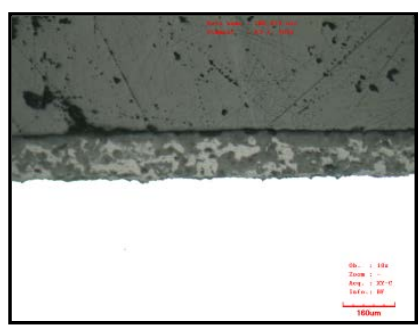

Fig. 7. Lacquered layer A3-1 (a)

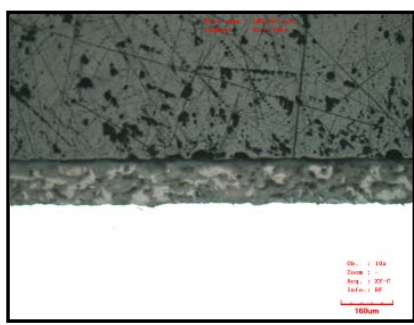

Fig. 9. Lacquered layer B3-3 (a)

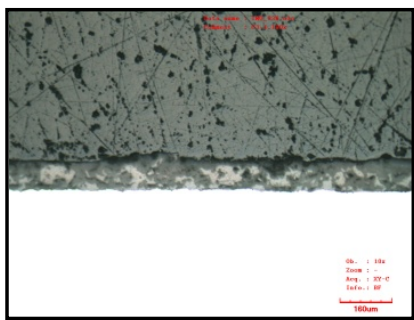

Fig. 11. Lacquered layer C3-1 (a)

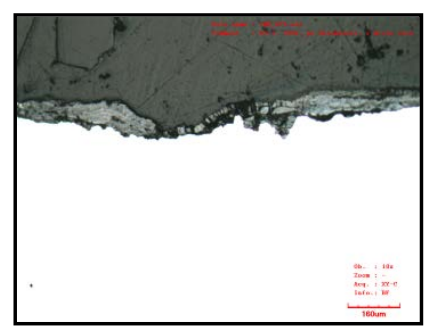

Fig. 8. The surface after delamination in the place of the cut A3-1 (b)

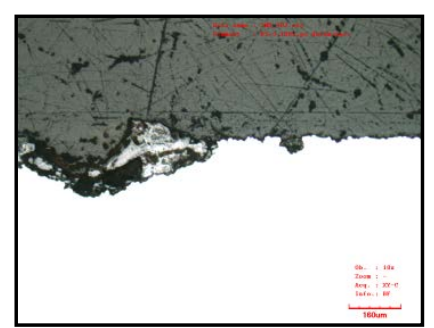

Fig. 10. The surface after delamination in the place of the cut B3-3 (b)

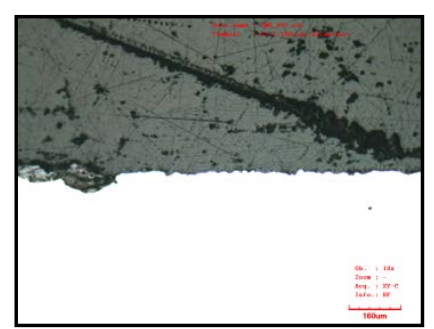

Fig. 12. The surface after delamination in the place of the cut C3-1 (b)
Sample B3-3 is attacked by uniform corrosion, as documented in Fig. 10. The surface material is breakdown to a depth of $180 \mu \mathrm{m}$. After $1000 \mathrm{~h}$ loading is preferably evaluated in combination sample chemical pre-treatment CC + Feph + Zr (Fig. 12.). Corrosion products can only be seen at the incision site. By the sample C3-1 occurred the smallest corrosion attack on the surface of the base material. Samples taken from the point (a), exhibit excellent adhesion to the surface of the base material for all samples (Fig. 7., 9., 11.). 


\section{Lacquered layer thickness measure- ment}

Within the microstructural analysis was performed measuring the thickness lacquer layer. From the measurement we can see, that the powder coating thickness on the sheet surface is uneven and different for each sample. Table 4. presents the measured lacquer thickness for samples that are documented above. The thickness of the coated layer was measured for each sample on a 10-point. In the Table 2. are given for illustration of the average thickness values of the lacquer layer.

Table 2 Lacquered layer thickness measurement

\begin{tabular}{|c|c|}
\hline Sample & $\boldsymbol{\varnothing}$ coating thickness [ $\boldsymbol{\mu m}]$ \\
\hline A1-1 & 232,86 \\
\hline B1-3 & 176,85 \\
\hline C1-1 & 142,86 \\
\hline A2-1 & 101,59 \\
\hline B2-3 & 139,71 \\
\hline C2-1 & 173,13 \\
\hline A3-1 & 147,19 \\
\hline B3-3 & 139,69 \\
\hline C3-1 & 88,77 \\
\hline
\end{tabular}

\section{Conclusion}

The research was focused on testing of the new pre-treatment based on nanotechnology. These nanoproducts could in the future replace traditional phosphating processes in the operations of companies that deal with finishes of materials and corrosion protection.

It can be concluded that the best results were achieved with triple chemical pre-treatment, i.e. pretreatment with alkaline degreasing + ferric phosphate + coating of zirconium nanopassivation. The second best pre-treatment after corrosive load is a combination of alkaline degreasing + zirconium nanopassivation. Samples without alkaline degreasing had the worst results and this procedure cannot be recommended as suitable for surface pre-treatment painted parts. Regarding the thickness of the lacquer layer, the lacquer thickness is considerably uneven. In order to better results comparable, it would be appropriate to achieve approximately the same thickness of paint on all sheets. Better compliance of the technological process in the application of powder coating can be recommended in this case.

\section{Literature}

1. MATERNE, T., BUYL, F., WITUCKI G. L. (2012). Organisilane Technology in Coating Application, pp. 16. Review and Perspectives, [online], [cit. 2012_07_25]. Available at www: http://www.dowcorning.com/content/publishedlit/261402-01.pdf.

2. VOEVODIN, A. A., SHTANSKY, D. V., LEVASHOV, E., A., MOORE, J. J. (2004). Nanostructured Thin Films and Nanodispersion Strengthened Coatings. Springer, Nato Science Series II: - Vol. 155, ISBN 1-4020-2221-2.

3. KUŚMIERCZAK, S., SVOBODOVÁ, J. (2012). Microscopic Evaluation of Protective Coating by Coated Sheets after Corrosion Load, pp. 151-157. Manufacturing Technology, Journal for Science, Research and Production, Vol. 12, No. 13, ISSN 1213-2489.

4. CAVALEIRO, A., HOSSON, J. T. (2006). Nanostructured Coatings, pp. 648. Nanostructure Science and Technology, Springer, ISBN 0-387-25642-3.

5. KLIMECKA-TATAR, D. (2014). Importance of Development Factors in Company Dealing with Cataphoresis Coating Method, pp. 20-22. Production Engineering Archives, Vol. 2, No. 1, ISSN 2353-7779

6. ADHIKARI, SAIKAT, K. A. UNOCIC, Y. ZHAI, G. S. FRANKEL, JOHN ZIMMERMAN \& FRISTAD (2011). Hexafluorozirconic acid based surface pretreatments: Characterization and performance assessment, pp. 1912-1924. Electrochimica Acta, Vol. 56, No. 4, [online], [cit. 2013-07-01]. Available at www: http://www.sciencedirect.com/science/article/pii/S0013 468610009692

7. NDREATTA, F. a kol. (2011). Development and industrial scale-up of $\mathrm{ZrO} 2$ coatings and hybrid organic-inorganic coatings used as pre-treatments before painting aluminium alloys, pp. $3-14$. Progress in Organic Coatings, Vol. 72, Issues $1-2$, [online], [cit. 2013-04-16]. Available at www: http://www.sciencedirect.com/science/article/pii/S0300 944011000294

8. SZKLARZYK, P., KLIMECKA-TATAR, D., SYGUT, P., LIPIŃSKY, T. (2014). Quality Analysis of the Plates for a Car Industry, pp. 11-13. Production Engineering Archives, Vol. 4, No. 3, ISSN 2353-7779 